\title{
A Quick Response: QR Code Use at the Harold B. Lee Library
}

Michael J. Whitchurch

Brigham Young University - Provo, michael_whitchurch@byu.edu

Follow this and additional works at: https://scholarsarchive.byu.edu/facpub

Part of the Library and Information Science Commons

Original Publication Citation

The Reference Librarian, 53:392-402

\section{BYU ScholarsArchive Citation}

Whitchurch, Michael J., "A Quick Response: QR Code Use at the Harold B. Lee Library" (2012). Faculty Publications. 1541.

https://scholarsarchive.byu.edu/facpub/1541

This Peer-Reviewed Article is brought to you for free and open access by BYU ScholarsArchive. It has been accepted for inclusion in Faculty Publications by an authorized administrator of BYU ScholarsArchive. For more information, please contact ellen_amatangelo@byu.edu. 
Title:

A Quick Response: QR Code Use at the Harold B. Lee Library

Author: $\quad$ Michael J. Whitchurch

Learning Commons Department Chair

Harold B. Lee Library, Brigham Young University

$3325 \mathrm{HBLL}$

Provo, UT 84602

michael whitchurch@byu.edu

Abstract: QR (Quick Response) code use in libraries is just beginning to evolve. The current uses of QR codes are varied and the future potential is vast. At the Harold B. Lee Library of Brigham Young University two projects have been implemented which use QR codes. This article presents details of these implementations and briefly describes QR code uses at other libraries. In addition, some pros/cons, cautions, and potential implementation issues are discussed.

Keywords: QR Codes, Audio Tour, Group Study Room Reservation, Mobile Libraries, Point of Need 
Introduction

As QR (Quick Response) Codes become more mainstream in industries such as inventory management and advertising, libraries are beginning to see the advantages and benefits of using this technology. These two-dimensional codes are similar to bar codes, but are much more versatile. When scanned with the camera on a mobile device (i.e. smart phone, iPod, or tablet), these codes provide the ability to capture much more than numeric information. Most commonly used on smart phones, the captured text can refer the user to a webpage, initiate a phone call, begin an e-mail, or save other textual information to the device.

QR codes, developed for inventory management by Denso Wave, a subsidiary company of Toyota, are useful because of their flexibility and versatility. While bar codes, used on products purchased at a store, are useful for simple numeric data, QR codes expand the concept to use any type of alpha-numeric character. In fact, a QR code can be used for up to 1,817 Japanese Kanji/Kana characters or up to 7,089 numeric only characters. An added value for using QR codes is the ability to customize the design of the codes; the codes can be made to allow for up to a 30 percent loss of the code (Chan, 2011). This allows for the display of an image, such as a company logo, in the code, which can personalize the look.

The Harold B. Lee Library (HBLL) at Brigham Young University (BYU) has implemented QR codes to provide context or location specific information, giving point-of-need assistance to patrons who use the library. After a brief review of implementations of QR codes at other libraries, this paper will describe the current projects at the HBLL, including some lessons learned and guidelines on implementation. In addition, it will discuss future projects and other potential implementations of QR codes, along with potential roadblocks that may be encountered.

Applications at Other Institutions 
Though QR codes have been used for years in Japan for inventory management, potential uses of these 2D codes have not yet been fully realized in other industries, such as libraries. Early adopters struggled to find implementations that would be useful to and used by their constituency, especially since devices needed to read the codes were not widely owned. Higher education has lagged behind other industries in implementing this technology, partially due to lack of knowledge of the codes and their benefit. An academic technologies survey, performed at BYU in March 2010, showed that while 91 percent of the students owned a cell phone, only 14 percent owned a smart phone (Unpublished BYU report, 2010). Though the numbers of smart phone owners is steadily increasing, this low adoption rate of smart phones at BYU is another reason QR codes are slow to catch on.

Uses of QR codes are as varied as the institutions where they are being used, as shown below. The possible uses are limited only by the creativity of those attempting to use them. As mentioned earlier, QR codes can represent any type of alpha-numeric data. Current uses can be categorized into two types: 1) information transfer and 2) linking to the web. Information transfer is the simplest use of the codes because it does not require Internet access on the $Q R$ reading 60 device-the $Q R$ code itself transfers the information. Examples of information transfer include phone numbers, addresses, or other contact information and event details on posters. The other type of code use is linking to the web which requires a connection to the Internet, whether by Wi-Fi or cell phone signal. The transfer of a URL to the phone from the QR code connects directly to the Internet-based content. Potential uses of this type of QR Q3 code include linking to multimedia (i.e., audio, video); Web sites for further information about an exhibit; and campus or building maps.

\section{Information Transfer}

At the Ryerson University Library (Anonymous, 2011) and the University of Huddersfield (Walsh, 2010), QR codes are used in the library catalog to save the title, call number and location of an item to a 
smart device. When a patron searches the library catalog, the details page for each item displays the author, title, call number, etc. as well as a dynamically generated QR code that can be scanned to save information, necessary for finding the item in the library, to their smart deviceThis replaces the need to write down, e-mail, or take a picture of the computer monitor for future use. This can help the users who "may write down incomplete information from the catalogue screen and become frustrated when they then fail to find the item" (Walsh, 2010, p. 6). Although the libraries at Ryerson and Huddersfield do not provide it, this implementation could also contain a link to a map with 80 the location of the item.

Using QR codes for promotional materials is one of the easiest and most effective ways to present information that can then be easily recorded for later use. The University of Technology, Sydney (McDonald, 2010), The Technical University of Catalonia (TUC) (Vila, Pérez, \& Campos, 2010), and Contra Costa County Library (CA) (Hadro, 2010) all use QR codes for promotion on posters, bookmarks, and other marketing materials. In addition to providing another way to record information, this is also a great opportunity to educate users about QR codes simply by displaying the code and letting natural curiosity drive the investigation.

\section{Linking to the Internet}

QR codes linking to the Internet involves creating a code that transfers the text of a URL to the device, thus providing a link to online content without the need to type in a complex string of characters. This content can be anything from a web page to multimedia or other content with information about the item or location to which the code is attached (e.g. an exhibit piece, library floor map, etc.). Though more complex than information transfer, the potential uses are even greater. Anything available online can be referenced through use of a QR code. There are also more published examples of this type of use in the literature. Many examples of QR code use in libraries are listed at 
Library Success: A Best Practices Wiki, a community developed page (Anonymous, 2011). If there is no citation with the examples mentioned here, the information comes from that page.

The University of Bath (Robinson, 2010) and Ryerson University Library (McCarthy \& Wilson, 2011) use QR codes as a means of providing a library audio tour via an MP3 download to the mobile device. Half Hollow Hills Community Library uses QR codes on the ends of ranges linking patrons to subject guides related to that selection of books (Anonymous, 2011). Abilene Christian University uses the codes to link to a search string in its catalog, displaying results of a search done by a librarian on a specific topic (Anonymous, 2011). The University of Huddersfield uses QR codes linking users to instructional videos, referring patrons from print resources to electronic versions (e-books and journals), and to link to further information on the Internet (Walsh, 2010). The Rector Gabriel Ferraté Library (Technical University of Catalonia) uses the codes to link to "registration forms to use the computer facilities in the library" (Vila et al., 2010, p. 332).

An innovative application of this type of linking is seen at the Contra Costa County Library. In connection with its "Snap \& Go Project," QR codes are placed in public transportation vehicles, linking commuters to online audio books (Anonymous, 2011). Similar to what Contra Costa is doing, is an implementation not by a library but by a bank. First Bank in Denver placed ads in the Denver International Airport with QR code links to free books. The books linked from the codes "were 'free' out-of-print classics" (King, 2011), but it appears that a bank beat many libraries to a service that could be extremely useful to readers.

The above list of uses is a small sampling of the potential applications of QR code use for libraries. The rest of this article will address how the Harold B. Lee Library at BYU has used, and plans to use, QR codes for library services.

The BYU HBLL Applications 
Research into QR codes led to brainstorming for applications of QR codes in the Harold B. Lee Library. We determined that the codes should only be used to facilitate library use and to improve services to students, not just use them because they are "trendy". In other words, applications needed to add value to the user experience; otherwise the codes would potentially not be used. The most important factor in deciding how to use QR Codes was point-of-need. We began by working with a program that already functioned in the library: the library audio tour.

\section{Library Audio Tour}

Freshmen at BYU are required to take a first-year-writing course; Writing 150: Writing and Rhetoric, or Philosophy 150: Reasoning and Writing. These courses include a unit dedicated to academic research and provide instruction on using the university library. At the end of the unit each student should have developed and written a well formed research paper. Each course section visits the library during two of the class sessions where students learn about print and electronic resources available in and through the HBLL and how to use them for academic research. Before the library sessions, however, students should have completed a tour of the library, followed by a post-tour quiz in Blackboard. The tour introduces students to the various areas of the library and can be taken in one of a variety of modes: check out an MP3 player from the library; download the MP3 files to a personal audio player; a virtual tour; or using QR codes (Whitchurch, 2011). Information about each of these modes is available to the students through their instructor and in a Blackboard course developed by HBLL instruction personnel which communicates with the students about library research.

The original tour was linear containing directional information, leading the listener from one area of the library to the next. For the QR code mode of the tour, the MP3 audio files were edited to remove all directional information, leaving only the content describing the areas of the library. The audio files were uploaded to the Internet and each QR code (e.g. Figure 1) was placed prominently in 
the corresponding area so students would be able to see and use the codes to hear information about the area. Students were also encouraged to print out a map

(http://lib.byu.edu/sites/qrcodes/files/2011/02/audiotourhandout.jpg) showing the location of each code. In order to complete the post-tour quiz each location needed to be visited. The map provided a visual reference of the library as well as a way to ensure that all QR codes had been visited.

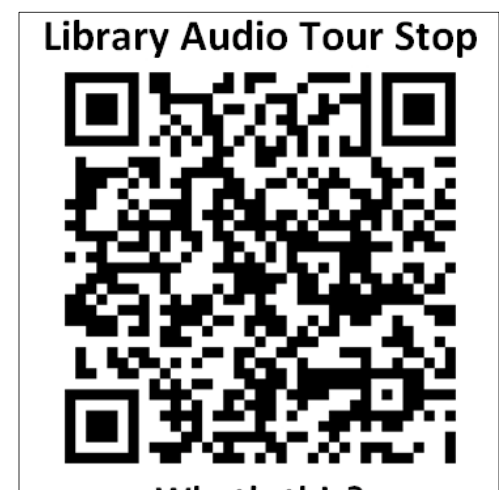

What's this?

http://lib.byu.edu/sites/qrcodes/

Figure 1. Library Audio Tour QR Code

Marketing/Promotional Materials

At the HBLL, QR codes have been used minimally on promotional or marketing materials. They have been included on banners outside the library promoting exhibits being held in the library. The codes link to the online exhibits, hours, location, and further exhibit information, including any online resources. Admittedly, the HBLL has not implemented this type of QR code use in a very effective or comprehensive way.

Group Study Room Scheduler (GSR)

The project using QR codes that we are currently most excited about is using QR codes for Group Study Room (GSR) scheduling, by way of the mobile enabled scheduling site (http://groupstudy.lib.byu.edu/m/). QR codes are placed near the room number of each of the 47 group study rooms in the library. The codes (e.g. Figure 2) link directly to a page for reserving the specific room. This web page allows the student to: 1 . reserve the room on the spot, if available; 2 . 
reserve the room for a later available time; or 3. reserve a different room. The purpose of this implementation is to provide point-of-need access for reserving a GSR. Often students enter the library looking for a space for group study without having reserved a room beforehand. Having the codes available at the room allows for making a reservation without needing to find a library computer or boot-up a personal laptop. Each of the GSR pages is tagged with Omniture (http://www.omniture.com/en/) web analytics code that tracks use of the pages. Though we have no way of tracking how many reservations are actually made through the QR codes we do track how often the codes are scanned. The statistics show that monthly numbers range from 95 , in the middle of the summer, to 382 during February 2012. This shows that the codes are being scanned and hopefully indicates the scans lead to room reservations. These statistics will be combined with the number of smart devices from the 2011 Academic Technologies survey (Unpublished data, BYU report, 2010) to help refine this implementation.

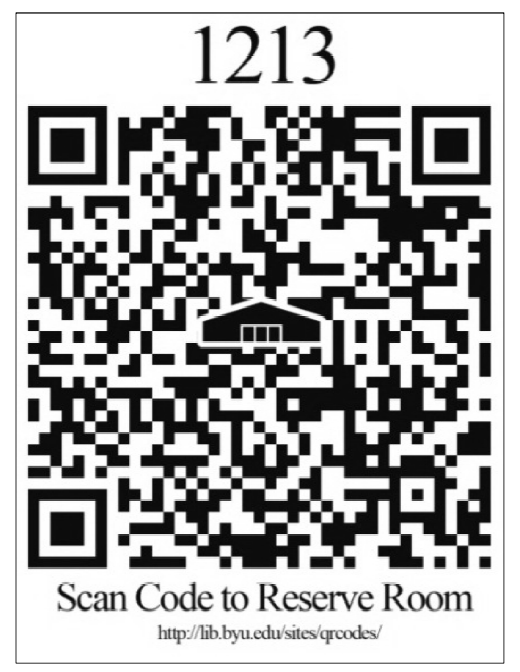

Figure 2. Group Study Room

Reservation QR Code

Lessons Learned

QR codes are a relatively new technology in the library community. Because of this, not many patrons know about the codes, though most have seen at least one without knowing what it was. To remedy this, we must market, promote, and otherwise educate our community about the codes, 
especially how we use them. The best promotion is simply placing them in visible locations with relevant and useful content. The content linked from the codes needs to be of value to the patron; the content needs to be worth the effort. Responsibility for this rests in the hands of all library employees. Each employee of the library should be educated on QR codes and how they work to help provide content that will be useful. This requires a basic understanding of how the library will use them, especially what type each code is (information transfer or link to the Internet). Though not many patrons use the codes, general knowledge of them will increase with use, especially as mass media and marketing continue to increase usage. They are easy and cheap to produce (free to create using sites such as http://www.beetagg.com or http://keremerkan.net/qr-code-and-2d-code-generator/), allowing for quick and simple implementations.

As QR codes are implemented for various services, their continued benefit must be proven. Statistics are an important element of any library service, helping to show its usefulness. Though producing and managing them is easy, QR codes need to be evaluated along with other services. In academia it is especially important to show that necessary funding, small though it may be, should be continued to maintain and perhaps expand the use of QR codes. Usage statistics regarding the codes can not only help provide support for their continuance, but can also provide guidance when trying to improve the usefulness for the students.

QR codes use can be tracked in a variety of ways. Commercial sites, such as beetagg (http://www.beetagg.com), which has both a free and a for-fee option, can provide this type of tracking. However, the nature of online services is volatile, meaning the service may not remain constant, in price or existence. For these reasons the HBLL has used different in-house methods of tracking QR code usage, though commercial services have not been entirely dismissed. The first implementation of QR codes used for the library audio tour tracked statistics in a round-about way. Each QR code links to an 
HTML page which contains two pieces of important code. The first is Omniture code that tracks the number of visits to the page. The second piece of code is a redirect that forwards the user to the requested file (i.e. mp3 file). This is seamless for the user and helps track usage. For the Group Study Rooms, it was simpler because each of the rooms already had a webpage created in which the Omniture code could be placed for tracking. (Note: not all implementations necessarily need to be tracked like those described above. For example, implementations where the code simply transmits information to the phone, in the case of event information, need not be necessarily tracked.)

Because usage of QR codes at BYU is so new, we were unsure how students would react to or use the codes. For this reason, codes were first produced cheaply using regular printer paper mounted on foam core. These have proven to be less durable than expected, but since we were anticipating replacing them with more permanent signs it seemed the best direction. The signs used for more permanent QR codes can be produced in a sign shop, using materials that are durable and resistant to fading.

When testing the codes it is important to use people who will be using the codes. This may sound obvious, but in the case of the library audio tour it proved to be essential. When implementing the library audio tour QR codes, the first test (alpha test) was done using student library employees. Feedback from them was very helpful, but it wasn't until the freshman students, those enrolled in five Writing 150 classes, started using the codes, that better, more relevant feedback was received. Because we listened to the students, the service has improved. Code locations were changed, code size increased, and audio was edited for better comprehension.

Future Plans

Now that QR codes have been implemented in the three above-mentioned ways, we are trying to improve and expand what we have done to make the codes more visible, attractive, and 
personalized. In addition, the codes need to be placed on more posters and promotional materials throughout the library. A proposal for QR code integration into the library has been presented to and approved by library administration, which will help pave the way to accomplish these improvements to existing implementations and increase exposure to the codes throughout the library.

Personalizing and customizing the QR codes is important in helping promote their use. The generic QR code is quite boring (black on white). The first implementation at the HBLL (library audio tour, see Figure 1) used the generic look, but for the GSR implementation, the codes were created using color. In addition, the codes include a simple iconic image in the middle. Modifying QR codes is relatively simple as long as some basic key concepts are followed. An article written by Hamilton Chan for Mashable (Chan, 2011) describes these keys and shows excellent examples of the concepts presented. Chan recommends using a color palette, softening the edges making the image more appealing to the eye, trying to "incorporate dimensionality for 3d impact," and remembering the 30 percent error correction in codes. The article is a great introduction to QR code modification.

For promotions, the library is currently using QR codes on only one poster outside the library. This type of implementation will expand to include codes on other posters, bookmarks, and exhibits. Many of the promotional materials can and should include library contact information, including IM, TXT, phone, or desk locations and hours.

Other projects being considered for the future will increase visibility and usefulness of QR codes. One option is to incorporate QR codes on the floor maps, located throughout the building, to help direct patrons to various areas of the library, including to a book using the call number. Some potential projects will require working with individual campus faculty, integrating library resources into the course. For example, a QR code on a course syllabus could be very helpful, linking students to the 
electronic reserves for the class, instead of having to type in the URL or follow many clicks to get to the same website.

\section{Practical Considerations}

Brainstorming cannot be underestimated in developing services using QR codes. Even the most radical or unrealistic suggestions can lead to great services for patrons. Each brainstorming session should include forward-thinking individuals who understand the library and its users, and are able to apply that knowledge to new services. Use those same people to help implement the codes in the library, and especially when performing user testing. Because producing and placing codes is so cheap and easy, perform a quick trial, having a few patrons use the codes and give feedback. This feedback should be used to improve each implementation.

Every institution is different and the use of QR codes will vary accordingly. For example, the HBLL audio tour is done in segments (tracks), whereas at the University of Bath the code links to a download of the entire tour for the third floor (Robinson, 2010). In addition, each type of library (i.e. public, academic, special, school, etc.) will have implementations that will serve the respective user group.

When deciding how to use codes, keep the following in mind: usefulness, usability, and code placement/visibility. Usefulness: the codes should have some value-add to the user, making it worth the time and effort to scan the code. If the code points to something that does not add value to the patron, then it will not be used. Usability: make the codes large and clear enough to scan without having to put forth too much effort to get to the proper distance to scan. A bad example of this is a large poster $\left(15^{\prime} x\right.$ $\left.5^{\prime}\right)$, about 25 feet from the sidewalk with a code only about eight inches square, definitely not scannable from that distance. Also, contrast is of utmost importance; some QR readers cannot read codes without a lot of contrast. Placement/visibility: the codes need to be placed in locations that are visible but also 
connected to the content of the "real world." Though the above-mentioned example was not usable, it was placed well and was visible. With the library audio tour at the HBLL, the codes were placed in the locations about which the audio speaks. However, comments from test users of the QR codes showed that some of the codes needed to be moved to more prominent locations. Again, listen to the users and follow their suggestions.

One final issue to consider when developing the $Q R$ codes is their management. A single project can require many codes. For example, the GSR project at the HBLL has 47 codes that need to be managed and the audio tour project has 21 codes. Between the two projects, there are almost 70 codes to be monitored. A development and management procedure should be created and followed to track changes related to the codes or to the content. This procedure should also include the process of creating and mounting the codes to ensure uniformity throughout the building. Periodic testing of all the codes should be a part of the management process, ensuring the content to which the codes link is still active and viable.

\section{Conclusion}

In this technology-rich age, where library users adapt to changes and adopt technologies so rapidly, libraries need to be flexible in developing and implementing services. Users continually look for ways to use technology to simplify their research or their information gathering. Libraries, therefore, need to leverage the users' technologies to create value-added services that will facilitate the information gathering and research processes.

Of the technologies that have been developed and used in libraries, QR codes provide a flexibility and breadth of opportunities for providing such learning possibilities not available in other ways. Many libraries have already begun implementing services using these codes, including the Harold B. Lee Library at Brigham Young University. All of the implementations mentioned above, including 
those at other institutions, can be used as a starting point for discussion at any institution about services that could benefit from the use of QR codes. As long as the basic keys are followed when implementing and designing the projects and the codes, they can become a great asset to the library. Listen to the users and use QR codes in ways that will create a value-added experience for them. Educate the users and provide helpful uses of the codes. Above all, be creative in the ways that the codes can be used in your institution by your unique set of users. 
References

Anonymous. (2011). QR codes. Retrieved 04/29, 2011, from

http://www.libsuccess.org/index.php?title=QR Codes.

Chan, H. (2011). How to: Make your QR codes more beautiful. Retrieved 05/05, 2011, from http://mashable.com/2011/04/18/qr-code-design-tips/.

Hadro, J. (2010). QR codes to extend library's reach in Contra Costa, CA. Library Journal. Retrieved from http://www.libraryjournal.com/lj/technologylibrary20/853479-

295/qr_codes_to_extend_libraryaposs.html.csp.

King, D. L. (2011). Give away some ebooks. Retrieved 04/29, 2011, from

http://www.davidleeking.com/2011/03/07/give-away-some-ebooks/.

McCarthy, G., \& Wilson, S. (2011). ISBN and QR barcode scanning mobile app for libraries. Code4lib, (13) Retrieved from http://journal.code4lib.org/articles/5014

McDonald, S. (2010). QR codes and the mobile web. InCite, 31(1), 19.

Robinson, K. (2010). Mobile phones and libraries: Experimenting with the technology. ALISS Quarterly, 5(3), 21-22.

Vila, M. C., Pérez, A. G., \& Campos, J. (2010). Mobile services in the rector gabriel ferraté library, technical university of catalonia. Reference Services Review, 38(2), 321-334.

Walsh, A. (2010). Blurring the boundaries between our physical and electronic libraries: Location aware technologies; QR codes and RFID tags. The Electronic Library, 2010 (9/14/2010). 
Whitchurch, M. J. (April 2011). QR codes and libraries: The library audio tour. Paper presented at the ACRL Conference, Philadelphia, PA. Retrieved from http://www.ala.org/acrl/sites/ala.org.acrl/files/content/conferences/confsandpreconfs/national/2 011/papers/qr_codes.pdf". 